\title{
Dealing with Iron and Other Micro-Irrigation Plugging Problems $^{1}$
}

Tom Obreza, Ed Hanlon, and Mongi Zekri²

\section{Introduction}

This publication is part of a series of documents dealing with proper installation, maintenance, and operation of micro-irrigation systems. These systems save water, reduce the potential for offsite loss of nutrients and agrochemicals, and directly contribute to yield and quality of many commercially-produced citrus and vegetables in Florida.

The objective of this document is to describe problems with emitter plugging and discuss management strategies to overcome and correct causes of plugging in micro-irrigation systems. This publication focuses, in particular, on iron scaling, documenting recent successes in treating this common problem in Florida. Information in this document should be of interest to vegetable and citrus producers, fertilizer and irrigation equipment dealers, Certified Crop Advisors, and other parties involved in the operation of micro-irrigation.

\section{Causes of Micro-Irrigation Plugging}

\section{Particulate Matter}

The primary cause of emitter plugging is foreign material, such as particulate matter (mainly sediment) from soil and/or the water source. These small inorganic particles may pass through filters and cause plugging at the micro-emitter. If the size of the particles exceeds the diameter of the emitter orifice, or if smaller particles stick together to form a much larger mass, then emitter plugging is likely.

Filters are the primary defense against particles entering the micro-irrigation system. The most economical solution is to buy the best filtration system you can afford, and then maintain that system according to the manufacturer's instructions.

Screen filters are the first line of defense for removing particles from the water source BEFORE particles are distributed throughout the irrigation system (pipe and tubing). This type of filter is designed to trap predominantly inorganic materials and will clog if elevated levels of organic materials enter the upstream side of the filter. Thus, if the water

1. This document is SL 265, one of a series of the Soil and Water Science Department, Florida Cooperative Extension Service, Institute of Food and Agricultural Sciences, University of Florida. Original publication date August 2008. Visit the EDIS Web Site at http://edis.ifas.ufl.edu.

2. Tom Obreza, professor, Department of Soil and Water Science; Ed Hanlon, professor, Department of Soil and Water Science, Southwest Research and Education Center (REC)--Immokalee; Mongri Zekri, multicounty extension agent, Hendry County; Florida Cooperative Extension Service, Institute of Food and Agricultural Sciences, University of Florida, Gainesville, FL 32611. 
source has both particulate matter and organic materials, screen filters should be placed in the system after filtration of the organic constituents. This multiple filter arrangement is often recommended for surficial water sources. For more information regarding screen filters, see: Screen Filters in Trickle Irrigation Systems http://edis.ifas.ufl.edu/WI009 .

Disk filters act somewhat like screen filters, and also target inorganic particles. Particles are trapped by adjacent disks as water flows from the outside edges toward the inside of the disks, which are placed close to each other. The filtered water exits the disk filter through a central conduit, leaving behind the grit between the disks. For more information regarding disk filters, see: Screen Filters in Trickle Irrigation Systems http://edis.ifas.ufl.edu/WI009.

Sand media filters can be effective for both inorganic and organic material removal. The media has specific properties (e.g. sharp-edged sand within a specific graded size) suitable for the foreign materials in the water source. This sand is placed in a retaining vessel and the source water is allowed to move slowly through it. Because of the volume of the media, these filters clog less than screen or disk filters, allowing for additional filtering capacity. For more information regarding sand media filters, see: Media Filters For Trickle Irrigation in Florida http://edis.ifas.ufl.edu/WI008.

\section{Biota}

Filtration can greatly reduce plugging problems; however, algae and other small plants and animals that live in, or seek, the water can still pass through the filters. Microbes that pass through the filters can continue to grow inside the system. Some organisms can build up in numbers, often forming clumps within the tubing at the point where water enters the emitter. Additionally, arthropods like ants may enter the emitter from the outside when the irrigation system is idle and become stuck in the tubing as they seek water, particularly when the system is turned on.

The least expensive treatment to control living organisms is injecting free chlorine into the micro-irrigation system to obtain 1 part per million (ppm) of free chlorine at the end of the system. To be effective, the amount of chlorine needed to achieve 1 ppm concentration at the far end should be injected EACH time the irrigation system is used. This technique is called continuous chlorine injection. The intent is to continuously introduce free chlorine at a relatively low concentration to prevent organic growth in the irrigation system. Super-chlorination -the so-called "shock" treatment -- does not require continuous free chlorine injection because it is usually done on a weekly basis. With this method, a much higher concentration of free chlorine is injected so that as much as $500 \mathrm{ppm}$ free chlorine is measured at the end of the irrigation system or zone.

WARNING: Super-chlorination may damage sensitive plants and irrigation system components. For more details regarding chlorination, please see: Treating Irrigation Systems with Chlorine http://edis.ifas.ufl.edu/AE080.

\section{Scaling}

Scaling may be caused by calcium or iron. These elements, usually associated with limestone or iron oxides, are often dissolved in the irrigation water source. Using this water for irrigation without treatment for calcium or iron can lead to scaling and ultimately plug the emitters or even irrigation system pipes.

\section{Calcium Scaling and Treatment}

Calcium is dissolved in water originating from groundwater aquifers, which are formed from limestone. Once brought to the surface, the calcium enters the irrigation system and may precipitate in the tubing or around and in emitters as calcium carbonate if the concentration is high enough or if the water $\mathrm{pH}$ changes. Preventing calcium from forming scale within the irrigation system is preferable to treating scale that has already formed. Calcium scale may be easily prevented with the injection of an appropriate concentration of acid, allowing the calcium to remain in solution and to exit the irrigation system harmlessly.

Typically, sulfuric acid and hydrochloric acid are the least expensive choices for this purpose. While any source of acid may be used to treat the calcium condition before it forms scale, all acids pose safety 
concerns regarding storage as well as personal safety. For more information regarding correction of calcium scaling, see: Neutralizing Excess

Bicarbonates From Irrigation Water

http://edis.ifas.ufl.edu/SS165; and Maintenance

Guide for Florida Microirrigation Systems

http://edis.ifas.ufl.edu/SS436

\section{Iron Scaling and Treatment}

Scaling caused by iron is more difficult to deal with than scale formed by calcium, and shall be explored in some detail. Iron is abundant throughout the earth, composing up to 5\% of the earth's crust. Hence, iron compounds are common. Given Florida's sandy soils and geologic time, iron compounds move through the soil and enter the shallow groundwater. Much of the rust or brownish red color found in many Florida soils is due to the presence of iron oxides and related compounds. Irrigating with iron-rich water may result in staining, not only of equipment, but also on foliage in contact with the water source. Within the irrigation system itself, iron scaling can reduce flow in pipes and clog emitters. When iron concentrations exceed $0.3 \mathrm{ppm}$, staining and scaling conditions exist. A review of groundwater concentrations in southwest Florida indicates that iron concentrations range from 0.1 to $7.0 \mathrm{ppm}$ (Obreza, 2003).

Iron chemistry is complex because ionic $\mathrm{Fe}$ can exist in two forms. The reduced cationic form, exhibiting two plus charges, is the ferrous form $(\mathrm{Fe} 2+)$. The ferrous form may be introduced into the irrigation system with the source water because this form of iron is soluble. Chemical conditions may change within the irrigation system itself, resulting in formation of a highly insoluble oxidized form with three positive charges (ferric, $\mathrm{Fe} 3+$ ). It is the ferric form that causes scale within the irrigation system. The maximum amount of ferric iron that can be retained in solution as ferric oxide is 0.6 parts per billion ( $\mathrm{ppb}$ ), considerably less than the iron concentrations reported above ( 0.1 to $7.0 \mathrm{ppm}$ iron) found in southwest Florida groundwater.

The conversion from ferrous (soluble) to ferric (insoluble) form is affected by several chemical parameters, the most important of which are oxygen content and water $\mathrm{pH}$. The ferrous form results when oxygen content of the water is low, such as in groundwater of many aquifers. When water is pumped from these locations into the irrigation system, it moves from an anaerobic condition to an aerobic condition with much higher levels of oxygen. When the ferrous form is exposed to oxygen, the result is a rapid conversion to the ferric form, with subsequent precipitation (scale). The $\mathrm{pH}$ of the water has an effect on the rate of this conversion (Table 1). Since many of the aquifers in Florida are limestone, the initial $\mathrm{pH}$ of water pumped from those aquifers is alkaline, often at or more than 8.0. Scale at this $\mathrm{pH}$ can form quickly once sufficient oxygen is present. Usually, sufficient oxygen is usually introduced throughout the irrigation system, and scale forms within the system, especially at or near oxygen sources such as leaking pipes or emitters (Table 1).

Table 1. Conversion of iron from ferrous to ferric forms in the presence of $2 \mathrm{ppm}$ oxygen at $70^{\circ}$ Fahrenheit.

$\begin{array}{ll}\frac{p H}{6.0} & \frac{\text { Time }}{100 \text { hours }} \\ 7.0 & 1 \text { hour } \\ 8.0 & \text { 30seconds }\end{array}$

\section{Controlling Iron Scaling}

The first step in controlling scaling of any type is to have field and laboratory tests completed on the irrigation water source. If a Mobile Irrigation Lab, typically associated with the local Soil and Water Conservation District, is operating in your area, lab personnel can test your water for plugging potential. Laboratory and field measurements are helpful in determining the plugging hazard(s) associated with the water source (Table 2).

This document shall primarily focus on problems with iron only. After identifying that the irrigation water source does contain sufficient iron to cause scaling (water testing is described below), several preventative strategies are available.

\section{Use of a Sedimentation Pond}

A sedimentation pond allows the oxygenation of the source water, and hence the precipitation of ferric iron, before the water is introduced into the irrigation system. Well water is pumped into a pond allowing equilibration of the water with the atmosphere. As 
Table 2. Interpretations to be used with laboratory water testing results, indicating the potential hazard from plugging of micro-irrigation systems.

\begin{tabular}{|c|c|c|c|c|}
\hline \multicolumn{5}{|c|}{ Plugging hazard based on concentration } \\
\hline Measurement & Units & Slight & Moderate & Severe \\
\hline Suspended solids ${ }^{1}$ & ppm & $<50$ & $50-100$ & $>100$ \\
\hline$p H$ & & $<7.0$ & $7.0-7.5$ & $>7.5$ \\
\hline Total dissolved solids ${ }^{1}$ & ppm & $<500$ & $500-2000$ & $>2000$ \\
\hline $\operatorname{Iron}^{1}$ & ppm & $<0.1$ & $0.1-1.5$ & $>1.5$ \\
\hline Manganese ${ }^{1}$ & ppm & $<0.1$ & $0.1-1.5$ & $>1.5$ \\
\hline Calcium $^{1}$ & ppm & $<40$ & $40-80$ & $>80$ \\
\hline Alkalinity as $\mathrm{CaCO}_{3}^{1}$ & ppm & $<150$ & $150-300$ & $>300$ \\
\hline Hydrogen sulfide ${ }^{1}$ & ppm & $<0.2$ & $0.2-2.0$ & $>2.0$ \\
\hline Bacteria & $\# / \mathrm{mL}$ & $<10,000$ & $10,000-50,000$ & $>50,000$ \\
\hline
\end{tabular}

${ }^{1}$ Concentration as $\mathrm{mg} / \mathrm{L}$ or parts per million (ppm).

Factors in italics: Measure in the field if at all possible.

oxygen enters the water, ferric iron is formed and precipitates. Factors affecting the time needed for precipitation include water temperature, wind speed, depth and mixing of the water, aeration and wave action. A good first estimate for the minimum time required is several hours, especially if the water is aerated. After the iron precipitates, water is removed from the pond and conveyed into the irrigation system for subsequent filtering and distribution.

\section{$\underline{\text { Advantages of a Sedimentation Pond }}$}

A sedimentation pond permits the removal of iron from the system without any chemical treatment, leaving behind iron scale in the pond itself. Since most Florida aquifers are composed of limestone, initial water $\mathrm{pH}$ from these aquifers is quite high. The sedimentation pond, in addition to oxygenating the water to remove ferric iron, also allows time for the equilibration of the water with Earth's atmosphere and the dissipation of carbonates and bicarbonates. As the carbonates and bicarbonates dissipate from the water source, the initial high water $\mathrm{pH}$ is lowered 1 to $2 \mathrm{pH}$ units, improving water quality for irrigation.

\section{Disadvantages of a Sedimentation Pond}

Unfortunately, while the sedimentation pond improves water quality with respect to both iron and the high $\mathrm{pH}$ caused by carbonates, it is an open water source. The pond is likely to introduce organic materials and living organisms into the irrigation system.

A second disadvantage is that an additional pumpage is required between the pond and the irrigation system. The introduction of water to the pond from the well source and its subsequent withdrawal for use in irrigation system must be considered when designing the size of the sedimentation pond to minimize turbidity and the introduction of grit into the irrigation system.

A sedimentation pond requires two pumps as described above. Additionally, a properly sized sedimentation pond requires sufficient land surface, which may take a substantial tract of land out of production.

\section{Oxygenation and Filter Systems}

The next alternative in iron scaling prevention is much more high tech. This system includes a gas chlorinator, hydro-cyclone filters, sand media filters, and backup disk filters.

The gas chlorinator (Fig. 1) introduces chlorine gas into the water system, which causes the iron to oxidize (ferrous to ferric forms). The filtering system traps the scale that has formed before the scale is introduced into the remaining portions of the irrigation system. 


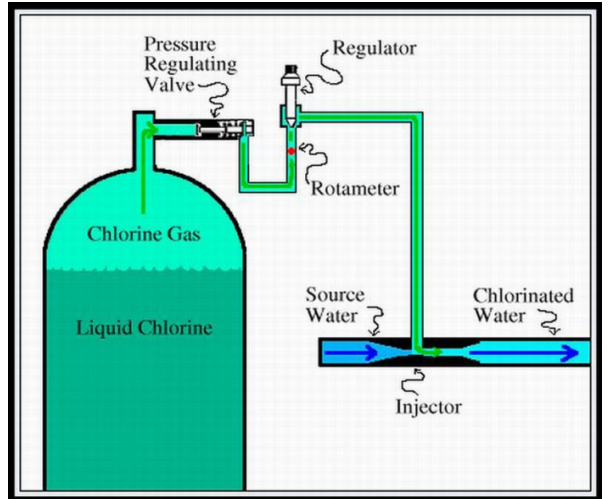

Figure 1. Diagram of a vacuum-type gas chlorinator used to treat irrigation water.

\section{Advantages of Oxygenation and Filtration}

Chlorine gas is relatively inexpensive. Using chlorine to oxidize iron from ferrous to ferric also provides active chlorine within the irrigation system to control microbial activity. This system also requires considerably less land area compared with the sedimentation pond system.

\section{Disadvantages of Oxygenation and Filtration}

Safety precautions for workers and equipment must be in place and followed correctly when handling chlorine gas. Because sand media filters are normally used to remove the scale, they require frequent backwashing (e.g. in 1-to-2 hour intervals).

\section{Irrigation Line Maintenance Chemicals}

In situations where iron has already formed, or as a preventive measure in situations where iron scale has been problematic for other users of the same water source, scale can be controlled by appropriate injection rates of chemicals, which can be grouped according to their reactions (Table 3).

Inorganic acids react quickly with water and solids to help prevent scale formation. The reaction is partially controlled by regulating the strength of the acid through dilution with water. In some cases, these acids may also supply nutrients after they have reacted in the irrigation system.

Chelating agents are organic compounds that sequester or occlude iron from further reactions by binding sufficiently tightly to the iron, removing it either as a free agent in solution or as scale. The iron is held by the chelating agent and the combined molecule flows out of the irrigation system. In some cases, the iron and other elements chelated by this group of chemicals may later serve as a nutrient source for the crop.

The last chemical group is of the reducing agents. These chemicals cause ferric iron to revert to ferrous iron, greatly increasing the solubility of the iron, which may then exit the irrigation system in solution. This group of chemicals can be quite reactive and yet can be handled and stored safely for agricultural purposes. Some of these chemicals are the byproducts of industrial processes, contributing to a so-called green re-use in the treatment of scale.

\section{Scale Removal from Irrigation Lines}

In addition to preventing iron scaling, many of these chemicals may help remove iron scale from irrigation tubing. The irrigation manager should understand that preventing scaling from forming in the first place is usually much more effective than trying to restore an iron scale-impaired system.

Research using selected chemicals indicates that some chemicals are much more effective at removing the iron scale from tubing than others (Figure 2).

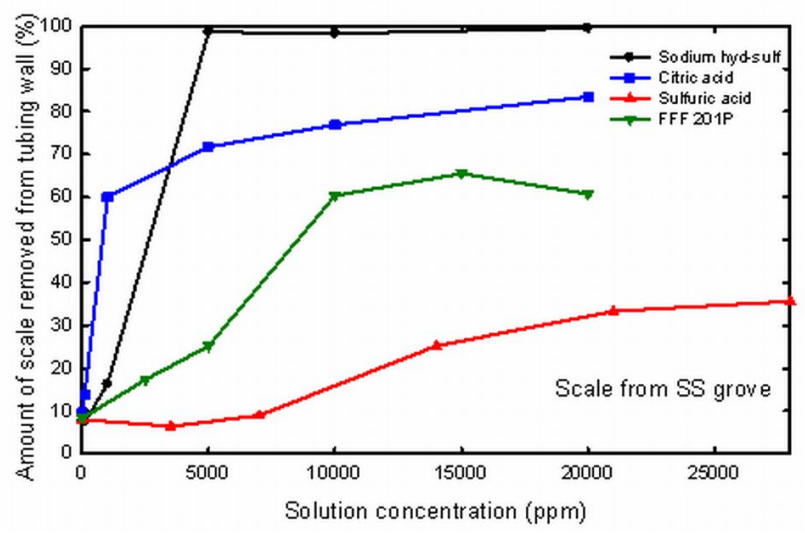

Figure 2. Efficacy of selected chemicals in removing iron scale from irrigation tubing.

Sodium hydrosulfite proved to be quite effective at removing scale. This reducing agent is also used to bleach paper and can present handling and safety issues for agricultural use that should be built into the farm safety program. However, this chemical is readily available from many sources, and proved to be the best chemical for removing scale in this study. 
The next best chemical was a chelating agent, citric acid, which is readily available from many sources and does not pose the same level of handling problems as sodium hydrosulfite.

The discharge water from systems treated with sodium hydrosulfite, a reducing agent, and citric acid, a chelating agent, turns different colors as scale is being removed from the system (Figure 3). The water from the sodium hydrosulfite contains ferrous iron, which is relatively colorless, while the chelated iron from the citric acid treatment remains in the ferric state, imparting a rust or reddish brown color to the flush water.

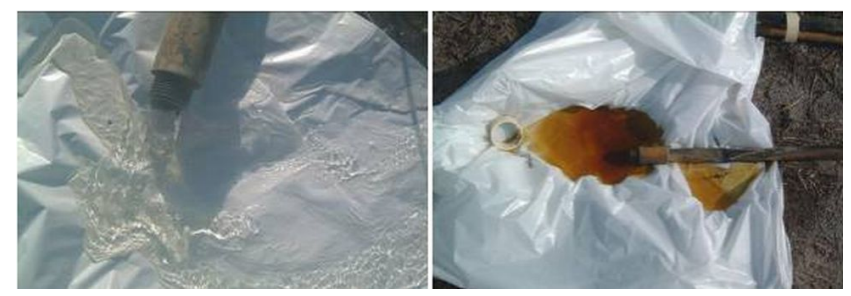

Figure 3. Flush water from treatment of scale using sodium hydrosulfite (left) and citric acid (right).

Sulfuric acid is a strong inorganic acid, often produced as a byproduct of many industrial processes. While sulfuric acid was the least effective chemical in this study, sulfuric acid is relatively inexpensive and can be safely handled with the proper equipment. As with many of the other chemicals, spill kits must be available and personal safety gear must be worn when handling sulfuric acid. Sulfuric acid may be most useful in situations where it is injected frequently in low concentrations. This acid may also be helpful in controlling microbial activity within the irrigation system through the appropriate regulation of water $\mathrm{pH}$.

In field trials, iron scale was removed to a greater or lesser degree based upon the selected chemical and the concentration with which that chemical was introduced into the scale-affected tubing (Figure 4). The reddish brown iron scale (see Water upper left, Figure 4) decreases as the concentration of the selected chemical is increased. Any one of the three chemicals at the higher treatment concentrations successfully treated this moderate scale problem.

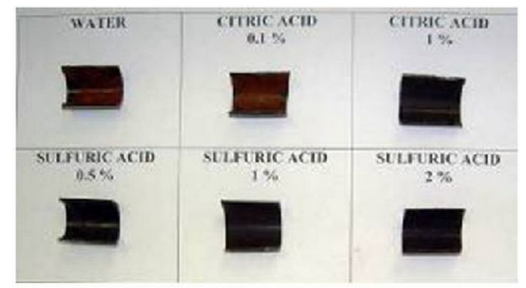

Figure 4. Treatment of iron scale formed within irrigation tubing with sulfuric acid, citric acid, and a proprietary product at selected concentrations. Iron scale on the inside of the tubing is evident by the reddish brown/rust color.

\section{Potential Problems for Treating Existing Iron Scale Irrigation Systems}

When any of these chemicals are introduced into a system that has been affected by iron, scale on the tubing walls may be removed. However, it is likely that some scale may flake off as a result of the treatment process, rather than being completely dissolved. The resulting iron scale flakes may in turn cause plugging at the emitter as the small particles build up.

To avoid this potential problem, the irrigation system should be flushed before injecting chemicals to treat the iron scale. For information concerning proper flushing of irrigation systems, see Maintenance Guide for Florida Microirrigation Systems. http://edis.ifas.ufl.edu/SS436; and Flushing Procedures for Microirrigation Systems. http://edis.ifas.ufl.edu/WI013.

After flushing, the irrigation system should be treated with the desired chemical concentration, letting the system sit idle for at least one day. This technique gives the chemical time to react with the iron scale, and yet does not move the iron scale particles to the emitters, preventing possible clogging of the emitters.Before using this system to irrigate, a second flush of the system will move iron scale particles out of the system and not adversely affect the emitters.

\section{Using scale-monitoring devices to evaluate cleaning}

A scale-monitoring device is a clean, non-scaled surface like a standard glass microscope slide within a PVC coupling (Figure 5) or short section of new tubing (Figure 6) that is spliced into an irrigation lateral line. These devices may be installed across the 
irrigation system network, from laterals close to the pump to those at the far end of the system. After installation, the irrigation system should be operated normally for several weeks or months, followed by periodic inspection of the devices for new scale deposition. When trying a new water treatment chemical, leave untreated at least one irrigation zone that draws from the same water source as the treated zones, and install scale monitoring devices in each. After a 4 - to 6 - week trial period of irrigation in treated and untreated zones, examine the scale-monitoring devices to see if less scale was deposited in the zone where the water treatment chemical was used.

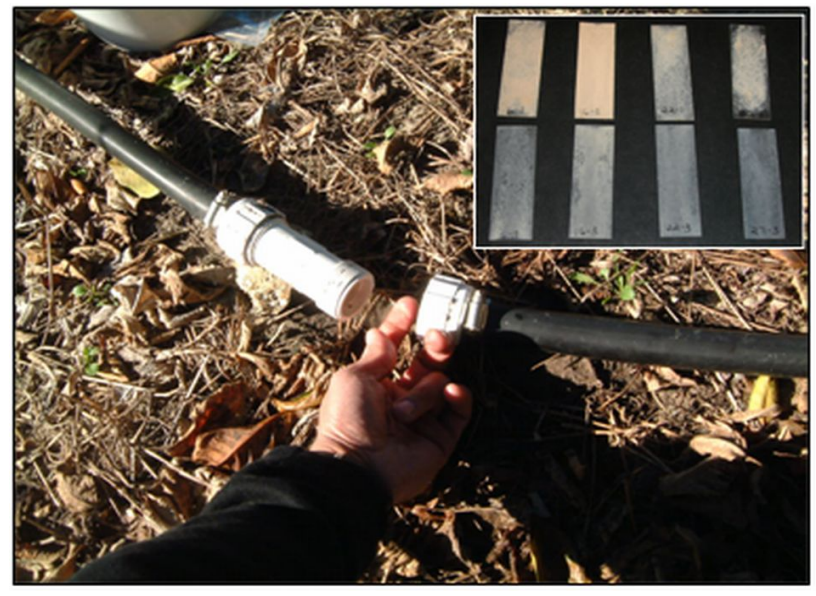

Figure 5. A 3/4-inch PVC coupling found in plumbing-supply stores serves well as in-line glass slide holder. Observing the amount, type, and rate of scale deposition occurring on a clean side (inset) can help determine the scaling potential of the irrigation water and the effect of injected scale-inhibiting chemicals.

\section{Summary and Concluding Remarks}

Proper filtration equipment is available to address many of the irrigation water quality problems faced by southwest Florida growers. Iron scaling is a common problem in some areas, and pre-treating the water before it enters the irrigation system is the most reliable way to avoid iron-related problems.

However, if the system has already been impaired by iron scaling, chemicals and management strategies are available to at least partially remediate the irrigation system. Treatment of existing scaling problems may increase the problems with plugged emitters due to particles of scale migrating to the emitters as the scale is removed from the tubing. Flushing, subsequent chemical treatment, and

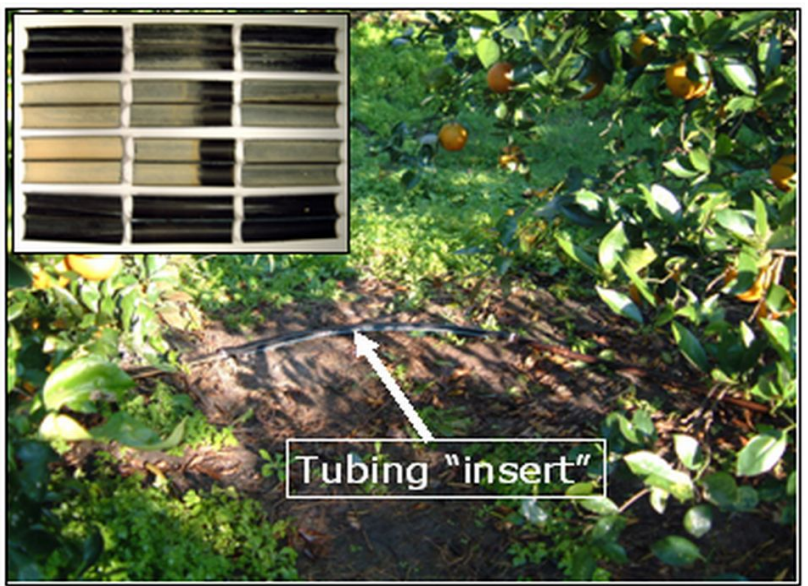

Figure 6. A short section of new plastic tubing "inserted" into an irrigation lateral can serve as a scaling indicator. After sufficient water has passed through the line, the insert can be removed and cut open to observe newly-deposited scale (inset). The amount, type, and rate of scale deposition occurring on the tubing wall can help determine the scaling potential of the irrigation water and the effect of injected scale-inhibiting chemicals. The effect of an injected purge chemical can be evaluated by installing a section of scaled tubing prior to treatment and observing the inside walls following system flushing.

additional flushing may also ameliorate some of the existing scale problems. Avoiding iron scale through the pretreatment of irrigation water is by far the best solution.

\section{For Further information}

Boman, B. 2002. Prevention of Emitter

Clogging. In Brian J. Boman (ed.). Water and Florida citrus. Univ. of Florida-IFAS publication SP 281.

Boman, B.J., P.C. Wilson, and E. A. Ontermaa. 2002. Understanding Water Quality Parameters for Citrus Irrigation and Drainage Systems. http://edis.ifas.ufl.edu/CH176 .

Clark, G.A., and A.G. Smajstrla. 2006. Treating Irrigation Systems with Chlorine. http://edis.ifas.ufl.edu/AE080.

Haman, D.Z., A.G. Smajstrla, and F.S. Zazueta. 2003. Media Filters for Trickle Irrigation in Florida. http://edis.ifas.ufl.edu/WI008.

Haman, D.Z., A.G. Smajstrla, and F.S. Zazueta. 2003. Screen Filters in Trickle Irrigation Systems. http://edis.ifas.ufl.edu/WI009 . 
Kidder, G., and E. A. Hanlon, Jr. 1998.

Neutralizing Excess Bicarbonates from Irrigation

Water. http://edis.ifas.ufl.edu/SS165

Obreza, T.A. 2004. Maintenance Guide for Florida Microirrigation Systems. http://edis.ifas.ufl.edu/SS436 .

Obreza, T. A. 2003. Increase Irrigation Efficiency and Eater Conservation Through Prevention of Micro-irrigation Emitter Plugging. Final report to South West Florida Water Management District.

Pitts, D.J., D.Z. Haman, and A.G. Smajstrla. 2003. Causes and Prevention of Emitter Plugging in Microirrigation Systems, Bull. 258, Fla. Coop. Ext.
Ser., IFAS, University of Florida. http://edis.ifas.ufl.edu/AE032 .

Simonne, E., and G.J. Hochmuth. 2003. Maintenance and Evaluation of Irrigation Systems Used for Vegetable Production in Florida in the BMP Era, http://edis.ifas.ufl.edu/HS167 .

Smajstrla A.G., and B.J. Boman. 2002. Flushing Procedures for Microirrigation Systems. http://edis.ifas.ufl.edu/WI013 .

Gary A. Clark, G.A., and A.G. Smajstrla. 2006. Treating Irrigation Systems with Chlorine. http://edis.ifas.ufl.edu/AE080 .

Table 3. List of irrigation line treatment chemicals, grouped by chemical reaction.

Inorganic acids

Hydrochloric acid

Phosphoric acid

Sulfuric acid

Nitric acid

Sulfamic acid

\section{Chelating agents}

Citric acid

Glycolic acid

Malic acid

Gluconic acid

Oxalic acid

Sodium EDTA

Sodium citrate
Reducing agents

Sodium sulfite Sodium hydrosulfite

Sodium metabisulfite

Italics indicate readily available products that were included in a recent iron scale study in southwest Florida (See Obreza, 2003).

Table 4.

\begin{tabular}{||l|l|l|l||}
\hline \hline Chemical agent & Where to purchase & Handling & Notes \\
\hline $\begin{array}{l}\text { Sodium hydrosulfite, } \\
\mathrm{NaS}_{2} \mathrm{O}_{4} \\
\text { (also called sodium dithionite) }\end{array}$ & $\begin{array}{l}\text { Industrial chemical supply } \\
\text { outlets }\end{array}$ & $\begin{array}{l}\text { Strong reducing agent; } \\
\text { Safety precautions are } \\
\text { required }\end{array}$ & $\begin{array}{l}\text { A sodium hydrosulfite solution must } \\
\text { be use immediately because the } \\
\text { chemical decomposes in water. }\end{array}$ \\
\hline Citric Acid, $\mathrm{C}_{6} \mathrm{H}_{8} \mathrm{O}_{7}$ & $\begin{array}{l}\text { Farm or industrial } \\
\text { chemical supply outlets }\end{array}$ & No special precautions & \\
\hline Sulfuric Acid, $\mathrm{H}_{2} \mathrm{SO}_{4}$ & $\begin{array}{l}\text { Industrial chemical supply } \\
\text { outlets }\end{array}$ & $\begin{array}{l}\text { Strong acid; Safety } \\
\text { precautions are required }\end{array}$ & \\
\hline \hline
\end{tabular}

